\title{
LA-UR-17-29235
}

Approved for public release; distribution is unlimited.

Title: $\quad$ Report on Beryllium Strength Experiments Conducted at the TA-55 $40 \mathrm{~mm}$ Impact Test Facility, Fiscal Year 2017

Author(s): $\quad$ Anderson, William Wyatt

Hollowell, Benjamin Charles

Martinez, Todd P.

Owens, Charles Thomas

Rivera, Joseph Lee

Intended for: Report

Issued:

2017-10-10 
Disclaimer:

Los Alamos National Laboratory, an affirmative action/equal opportunity employer, is operated by the Los Alamos National Security, LLC for the National Nuclear Security Administration of the U.S. Department of Energy under contract DE-AC52-06NA25396. By approving this article, the publisher recognizes that the U.S. Government retains nonexclusive, royalty-free license to publish or reproduce the published form of this contribution, or to allow others to do so, for U.S. Government purposes. Los Alamos National Laboratory requests that the publisher identify this article as work performed under the auspices of the U.S. Department of Energy. Los Alamos National Laboratory strongly supports academic freedom and a researcher's right to publish; as an institution, however, the Laboratory does not endorse the viewpoint of a publication or guarantee its technical correctness. 


\section{Report on Beryllium Strength Experiments Conducted at the TA-55 40 mm Impact Test Facility, Fiscal Year 2017}

William W. Anderson, Benjamin C. Hollowell, Todd P. Martinez, Charles T. Owens, and Joseph L. Rivera 


\section{Report on Beryllium Strength Experiments Conducted at the TA-55 $40 \mathrm{~mm}$ Impact Test Facility, Fiscal Year 2017}

William W. Anderson, Benjamin C. Hollowell, Todd P. Martinez, Charles T. Owens, and Joseph L. Rivera

\section{Introduction.}

A series of experiments is currently in progress at eth $40 \mathrm{~mm}$ Impact Test Facility (ITF), located at TA-55, to understand the strength behavior of Beryllium metal at elevated temperature and pressure. In FY 2017 , three experiments were conducted as a part of this project.

\section{Experiments.}

Figure 1 presents a schematic of the basic experimental configuration. The basic experimental approach is to conduct double-shock experiments in which a Be sample is impacted by a two-layer impactor consisting of a lower impedance front layer and a higher impedance rear layer. For all experiments in this series, the front layer is OFHC Cu and the rear layer is $\mathrm{W}$. The rear surface of the sample is impacted by the layered impactor. A 100-oriented single-crystal LiF window is glued to the front surface of the sample. A thin vapor-deposited layer of Al on the sample-side of the window serves as a reflector for optical diagnostics. The sample-window interface is monitored with VISAR and PDV velocimetry.

The experimental plan calls for three pressure-matched experiments to be conducted at each of two first-shock pressures. The first set of experiments, conducted in FY 2017, was conducted at a nominal first-shock stress of 75 kbar. The experiments consisted of one drive characterization experiment and two Be strength experiments. In the drive characterization experiment, a LiF window, without an attached sample, was impacted directly and the impact surface monitored in order to obtain a measurement of the detailed drive input to the sample. In the first of the Be strength experiments, the sample was impacted at nominal room temperature. It should be noted that, during the time period in which the experiments were conducted, the room temperature in the ITF ranged from 17 to $22^{\circ} \mathrm{C}$. In the second strength experiment, the sample was heated to a temperature of $200^{\circ} \mathrm{C}$ prior to impact.

For the purposes of planning, the equation of state parameters listed in Table 1 are used for the various materials in the experiments. In particular, the properties used for $\mathrm{Be}$ at $200^{\circ} \mathrm{C}$ are based on the room temperature properties, modified as described here. Haws [1988] presents thermal expansion coefficient data for S-200F Be from $100 \mathrm{~K}$ to $450 \mathrm{~K}$, which we assume can be extrapolated to $473 \mathrm{~K}$ with little risk. A quadratic fit to the data from $180 \mathrm{~K}$ to $450 \mathrm{~K}$ was performed and integrated to obtain the linear thermal strain and multiplied by 3 to obtain the volume thermal strain, with the result that heating from $298 \mathrm{~K}$ to $473 \mathrm{~K}$ is estimated to result in a $0.714 \%$ increase in specific volume. The elastic modulus results of Nadal and Bourgeois [2010] are used to obtain the fractional change in the bulk sound speed and this fractional change was applied to the Hugoniot intercept velocity. We use the volume dependence of the Grüneisen parameter presented by Lazicki et al. [2012] to obtain the value 


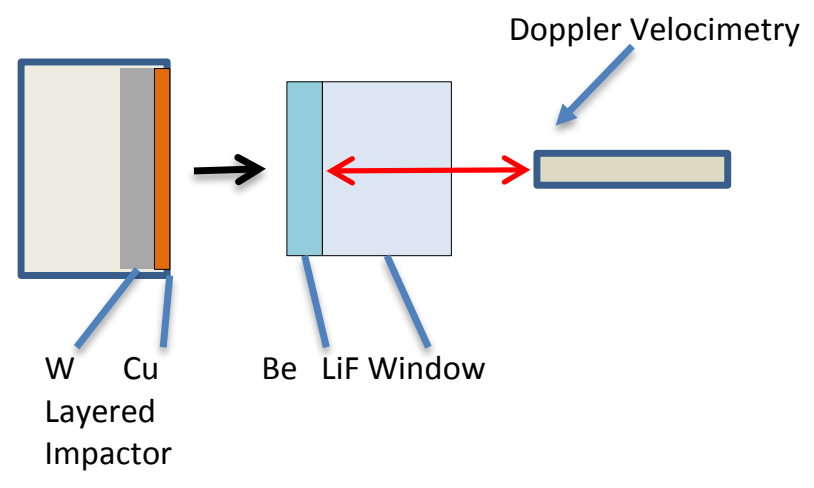

Figure 1. Schematic of beryllium experiments. In the drive characterization experiment, the Be sample is omitted and the window impacted directly.

\begin{tabular}{|c|c|c|c|c|}
\hline \multicolumn{5}{|c|}{ Table 1. Material properties used in the planning and analysis of the experiments. } \\
\hline Material & $\rho_{0}$ & $C_{0}$ & $s$ & $\gamma_{0}$ \\
\hline OFHC Cu & 8.930 & 3.9023 & 1.5153 & 1.96 \\
\hline $\mathrm{W}$ & 19.2345 & 4.022 & 1.26 & 1.65 \\
\hline $\operatorname{Be}(298 \mathrm{~K})$ & 1.851 & 7.998 & 1.124 & 1.16 \\
\hline $\operatorname{Be}(473 \mathrm{~K})$ & 1.8379 & 8.000 & 1.124 & 1.186 \\
\hline $\operatorname{LiF}(298 \mathrm{~K})$ & 2.6402 & 5.148 & 1.353 & 1.63 \\
\hline $\operatorname{LiF}(473 \mathrm{~K})$ & 2.5874 & 5.174 & 1.353 & 1.663 \\
\hline
\end{tabular}

corresponding to the initial density at $473 \mathrm{~K}$. Given the very small difference expected in the pressure derivative of the bulk modulus, we assume that the slope of the Hugoniot remains the same as the room temperature value. It should be noted that Be exhibits an elastic precursor that has an unusually long run distance to a steady state, so that the shock conditions calculated and presented in this report are necessarily approximate. The behavior of the elastic precursor at elevated temperature has not been investigated. Although Frazier et al. [2012] give data on the behavior of LiF at high temperature, we note that their starting density is unusually low. Here, we choose to use the thermal expansion results from Touloukian et al. [1977] to obtain the density at $473 \mathrm{~K}$ and adjust $\gamma_{0}$ to be consistent with this. We assume the value of $s$ is the same as the room temperature value. For $C_{0}$, we use the temperaturedependent elastic constant data of Jones [1976] to obtain a ratio of the bulk modulus at $473 \mathrm{~K}$ to that at room temperature and use that with the thermal expansion results to calculate the Hugoniot intercept. We use the original fit parameters of Carter [1973] for the room-temperature properties of LiF. The properties of $\mathrm{Cu}$ are from Anderson [2004] with an assumed standard density of $8930 \mathrm{~kg} / \mathrm{m}^{3}$ and Grüneisen parameter calculated from handbook values of measured quantities. The properties used for W are from Hixson and Fritz [1992], but with an initial density based on the average of impactor densities used in other recent experiments. 


\section{Results.}

Tables 2 and 3 present the details and shock states achieved in the experiments in this series. Figure 2 presents the velocimetry results of the drive characterization experiment (55-498-P58) and the roomtemperature experiment (55-500-P59), shifted to put impact at $t=0$. As of this writing, the measured densities of the samples have not been received, so the analysis thus far uses an assumed density for the $\mathrm{Be}$ of $1851 \pm 1 \mathrm{~kg} / \mathrm{m}^{3}$. The $\mathrm{Cu}$ and $\mathrm{W}$ densities were not measured and the values given are based on the standard density $\left(\mathrm{Cu}, \rho=8930 \pm 10 \mathrm{~kg} / \mathrm{m}^{3}\right)$ and the average value of impactors in previous shots $(\mathrm{W}, \rho$ $\left.=19345 \pm 115 \mathrm{~kg} / \mathrm{m}^{3}\right)$. Based on the data, the input first shock pressure to the Be in shot 55-500-P59 was $\sim 0.2 \%$ greater than that into the LiF window in shot 55-498-P58.

Because of requirements to redesign the heated target assembly based on previous experiments, shot 55-501-P60 was considered a high-risk experiment, with a significant probability of failure. During the experiment, care was taken to assure that all components of the triggering system, heating system, and diagnostics were operating as planned. At the time of the experiment, indications were that all components of the experiment were operating nominally. However, upon examination of the instrumental records, it was determined that none of the records contained data that could be interpreted in the context of the expected behavior of the experiment. The following observations concerning the experimental records are noted:

1. The diagnostic recording instrumentation triggered from the delay generator as expected.

2. The VISAR data show no evidence of laser light, indicating one of four possibilities: that the Pockels cell failed to trigger, that the laser ceased to emit light immediately prior to the experiment, that the reflective interface viewed by the VISAR was not in a position to reflect light to the VISAR at the time the Pockels cell gated, or that the VISAR probe fibers somehow moved and were cut by the projectile prior to impact.

3. PDV-1 shows only a continuous low-frequency sine wave over the entire recording period.

4. PDV-2 shows a signal that varies with time, including a long-duration oscillation consistent with a velocity of $22 \mathrm{~m} / \mathrm{s}$ at least $30 \mu \mathrm{s}$ prior to trigger. This signal returns late in time. At the time motion would be expected on the target, there is no discernable signal.

5. PDV-4, which was intended to view the projectile as it approached that target, shows no apparent periodic signal, indicating it did not observe the projectile or that the projectile was disrupted.

6. The barrel pins show definite well-defined pulses, but there are two apparent sets of pulses that are not totally consistent with one another.

7. The shorting pin signal recorded on the pin digitizers shows a slowly decaying oscillatory signal, with no indication of multiple pulses that should have occurred as different pins were contacted.

8. Because all of the diagnostics recorders were set to single trigger, there is no possibility of multiple triggers causing a late-time overwriting of the experimental data. As of this writing, limitations on access to the gun due to issues in at TA-55 have precluded performing a post-shot inspection of the gun or the shot debris that might provide information to help in diagnosing the shot. 


\begin{tabular}{|c|c|c|c|c|c|c|}
\hline \multicolumn{9}{|c|}{ Table 2. Shot parameters. } \\
\hline Shot & $\begin{array}{c}\text { Beryllium } \\
\text { Thickness } \\
(\mathrm{mm})\end{array}$ & $\begin{array}{c}\text { Glue } \\
\text { Thickness } \\
(\mathrm{mm})\end{array}$ & $\begin{array}{c}\text { Copper } \\
\text { Thickness } \\
(\mathrm{mm})\end{array}$ & $\begin{array}{c}\text { Tungsten } \\
\text { Thickness }(\mathrm{mm})\end{array}$ & $\begin{array}{c}\text { Glue } \\
\text { Thickness } \\
(\mathrm{mm})\end{array}$ & $\begin{array}{c}\text { Impact } \\
\text { Velocity } \\
(\mathrm{km} / \mathrm{s})\end{array}$ \\
\hline 498 & --- & --- & 0.999 & 2.046 & -0.002 & $0.6960 \pm 0.0005$ \\
\hline 500 & 3.9740 & -0.0005 & 0.999 & 2.107 & 0.001 & $0.6898 \pm 0.0011$ \\
\hline 501 & 3.9955 & 0.0090 & 0.996 & 2.093 & -0.002 & --- \\
\hline
\end{tabular}

\begin{tabular}{|c|c|c|c|c|c|c|c|c|}
\hline \multicolumn{9}{|c|}{ Table 3. Shock states achieved in experiments. } \\
\hline & \multicolumn{9}{c|}{ First Plastic Wave } \\
\hline Shot & $u_{p}(\mathrm{~km} / \mathrm{s})$ & $U_{s}(\mathrm{~km} / \mathrm{s})$ & $P(\mathrm{kbar})$ & $\rho\left(\mathrm{Mg} / \mathrm{m}^{3}\right)$ & $u_{p}(\mathrm{~km} / \mathrm{s})$ & $U_{s}(\mathrm{~km} / \mathrm{s})$ & $P(\mathrm{kbar})$ & $\rho\left(\mathrm{Mg} / \mathrm{m}^{3}\right)$ \\
\hline 55-498-P98 & -- & -- & --- & -- & 0.4918 & 5.817 & 75.96 & 2.8855 \\
& & & & & \pm .0016 & \pm .002 & \pm .27 & \pm .0008 \\
\hline $55-500-P 59$ & 0.0085 & 12.660 & 1.988 & 1.8522 & 0.4873 & 8.358 & 76.12 & 1.9648 \\
& \pm .0042 & \pm .312 & \pm .978 & \pm .0012 & \pm .0026 & \pm .106 & \pm .79 & \pm .0023 \\
\hline
\end{tabular}



Figure 2. Input wave profile (blue) obtained from shot 55-498-P58 and transmitted profile (green) obtained in shot 55-500-P59. 


\section{References.}

Anderson, W. W., LANL Memorandum DX-2:04-042, 2004.

Carter, W. J., High Temp. High Press., 5, 313-318.

Frazier, E., P. Antoine, J.-L. Godefroit, G. Lanier, and G. Roy, EJP Web Conf., 26, 01022-1-3, 2012.

Haws, W., Materion Data Sheet TM894, 1988.

Hixson, R. S., and J. N. Fritz, J. Appl. Phys., 71, 1721-1728, 1992.

Jones, L. A., Phys. Earth Planet. Inter., 13, 105-118, 1976.

Lazicki, A., A. Dewaele, and P. Loubeyre, Phys. Rev. B, 86, 174118-1-10, 2012.

Nadal, M.-H., and L. Bourgeois, J. Appl. Phys., 108, 033512-1-6, 2010.

Touloukia, Y. S., R. K. Kirby, R. E. Taylor, and T. Y. R. Lee, Thermophysical Properties of Matter, v. 13,

Thermal Expansion of Nonmetallic Solids, 1977. 